\title{
PENGARUH PENERAPAN METODE DEMONSTRASI TERHADAP HASIL BELAJAR PESERTA DIDIK MUATAN IPA KELAS IV DI SDN 102/II SUNGAI KERJAN
}

\author{
Michella Asfinivia ${ }^{1}$, Sonia Yulia Friska ${ }^{2}$, Rahmatul Hayati ${ }^{3}$ \\ 1,2,3 PGSD, FKIP Universitas Dharmas Indonesia \\ Email: michellaasfinivia@gmail.com
}

\begin{abstract}
ABSTRAK
Pemeriksaan ini dibangunkan oleh hasil pembelajaran yang rendah terhadap konten sains yang belum sampai pada kriteria kelengkapan minimum (KKM). Salah satu variabel yang berkontribusi adalah hasil pembelajaran yang rendah dari praktik, terutama dalam pembelajaran sains. Oleh karena itu, strategi pembelajaran yang tepat diperlukan yang memengaruhi hasil pembelajaran yang mudah dipahami. Tujuan dalam penelitian ini adalah untuk memahami seberapa banyak dampak metode dmeonstrasi terhadap hasil pembelajaran di kelas IV di SDN 102 / II Sungai Kerjan pada pembelajaran sains.

Jenis peneliitian ini merupakan peneliitian Pre Experimental Design dengan pendekatan kuantitatif. Design yang digunakan tipe One Grup Pretestt Posttestt Design. Subjek penelitian ini adalah peserta didik kelas IV C SD Negeri 102/II Sungai Kerjan yang berjumlah 27 orang. Dalam penelitiian ini, instrumen pengumpullan data peneliti menggunakan instrumeen berupa soal tes. Teknik pengumpullan data menggunakaan tes pilihan ganda yang berjumlah 20 soal pretest dan posttest. Data yang diolah menggunakan SPSS 22.
\end{abstract}

Kata Kunci: eksperimen, metode demonstrasi, hasil belajar, IPA

\begin{abstract}
This examination is awakened by low learning outcomes of science content that has not yett reached the minimum completeness criteria (KKM). One variable that contributes is the low learning outcomes of practice, especially in science learning. Therefore, the right learning strategy is needed which affects the results of easy-to-understand learning. The aim in this study was to understand how much impact the demontrasion method on the results of learning in class IV at SDN 102 / II Kerjan River in Science learning.

This type of research is a type of Pre Experimental Design research with a quantitative methodology. Design that uses the type of One Group Pretest Posttest Design. The subjects of this study were 27 students at SD Negeri 102/II Sungai Kerjan. In this examination, the data collection instrument of the researcher used an instrument in the form of test questions. The data collection technique utilizes up to 20 pretest and posttest questions. The data analysis technique used a statistical test, namely the Paired Samples TTest test because the data were normally distributed. Information handled using SPSS 22.
\end{abstract}

Keywords: Experiments, demonstration method, learning outcomes, science 


\section{PENDAHULUAN}

Visi dan misi yang tertuang dalam Sistem Pendidikan Nasional yang mengatakan bahwa "Persiapan berfungsi untuk menumbuhkan kemampuan siswa untuk mempertimbangkan dan membentuk karakter yang luar biasa. Sehingga pengganti negara mendapatkan pelatihan yang optimal. Bimbingan berarti membina siswa menjadi orang yang bertaqwa, bertakwa kepada Allah SWT. Dan memiliki etika yang tinggi, mahir, dan inovatif. Silviana et al., (2018) mengatakan bahwa pendidikan adalah suasana belajar-mengajar dan proses belajar yang efektif dan efesien yang didapatkan dibangku sekolah untuk mengembangkan pola pikir peserta didik serta untuk menumbuhkan kemampuan siswa yang memiliki karakter hebat, pengetahuan yang luas, memiliki keterampilan, sopan, serta mempunyai akhlak yang baik dalam hal apapun.

Sekolah adalah tempat para peserta didik mendapatkan pelatihan baik dari pendidik. Dari bangku sekolah yang diajar oleh pendidik untuk mendapatkan pembelajaran yang baik secara formal dan sistematis kepada peserta didiknya. Dengan menyelenggarakan pendidikan dan pengajaran terhadap peserta didik, dapat menjadikan peserta didik menjadi generasi yang memiliki kecerdasan, wawasan yang luas, pengetahuan yang luas, serta membentuk akhlak mulia dan karakter yang baik untuk mencapai tujuan yang diharapkan (Ade Putri, 2017).

IPA merupakan sebagai "ilmu pengetahuan alam yang bersifat umum, serta tersusun secara teratur yang menghasilkan suatu kumpulan data hasil observasi”. Pengetahuan IPA harus diketahui oleh peserta didik sejak mendapatkan pendidikan sekolah dasar karna pembelajaran IPA menjadi mata pelajaran utama untuk menumbuhkan pola pikir peserta didik secara logis, cermat, kritis serta efektif dan efesien. Dengan peserta didik menguasai pebelajaran IPA disekolah dasar, dapat berpengaruh positif terhadap hasil yang didapatkan.

Akibat dari persepsi yang peneliti temukan di SD Negeri 102/II Sungai Kerjan, unsur penyebab permasalahan yang ditemukan oleh peneliti yang utama adalah hasil belajar siswa pada pembelajaran IPA menurun. Faktor selanjutnya adalah dalam sistem pembelajaran peserta didik kurang berpusat pada pemahaman materi pembelajaran IPA. Didalam proses pembelajaran peserta didik beranggapan bahwa pembelajaran IPA pembelajaran yang membosankan, membuat jenuh dan tidak menarik dalam belajar. Meski mendapatkan pengajaran dari pendidik tentang IPA secara terperinci tetapi peserta didik masih kurang mengerti terhadap materi yang dijelaskan pendidik. Hal ini dikarenakan pengajar kurang tepat dalam memanfaatkan strategi pembelajaran yang membuat hasil belajar siswa rendah dan sistem pembelajaran kurang berhasil dan efektif. 
IPA merupakan pembelajaran yang penting dan dinamis, maka dari itu perlu adanya latihan-latihan belajar kepada peserta didik (Saputro, 2017). Jika kegiatan yang tepat dan cepat tidak diberikan dan memilih metode yang sesuai, maka pemahaman siswa terhadap materi sains sangat kurang. Friska Sonia Yulia, dkk, (2021) Pembelajaran yang bermanfaat di ruang belajar tidak hanya fokus pada siswa namun, pemilihan metode pembelajaran yang sesuai dengan materi pembelajaran sehingga tercapainya hasil belajar yang efektif.. Oleh karena itu, penting untuk memiliki teknik pembelajaran yang sesuai agar peserta didik mudah mempelajari materi yang disampaikan oleh pendidik, khususnya dengan menggunakan metode pembelajaran yang tepat yaitu menggunakan metode dmeonstrasi agar pembelajaran menjadi menarik dan tidak melelahkan serta lebih mudah bagi siswa untuk memahaminya. Serta mendapatkan hasil belajar yang lebih ideal. Hal tersebut didukung oleh hasil penelitian yang menyatakan bahwa keberhasilan seorang siswa dalam mencapai suatu hasil belajar yang optimal tentu tidak lepas dari peran seorang pendidik yang merupakan faktor terpenting dalam pembelajaran (Friska Sonia Yulia, dkk. 2020).

Faktor seorang pendidik juga dapat menentukan pencapaian pembelajaran di ruang belajar. Dengan penerapan metode pembelajaran yang kurang cocok di dalam proses pembelajaran sebagai salah satu penyebab rendahnya hasil belajar siswa (Friska Sonia Yulia, dkk, 2020). Maka dari itu dengan menerapkan metode demonstrasi di dalam pembelajaran, dapat mencapai hasil belajar yang baik. Metode demonstrasi merupakan strategi belajar yang digunakan oleh seorang pendidik dalam sistem pembelajaran. Pendidik menerapkan metode demonstrasi dengan menunjukkan suatu benda atau alat peraga di hadapan peserta didik. Dengan tujuan agar peserta didik lebih mudah memahami dan mudah untuk mendemonstrasikan materi yang diperkenalkan oleh pendidik (Wiranty, 2017).

Oleh karena itu, guru yang menggunakan strategi pembelajaran yang tepat sangat membantu pencapaian peserta didik dengan cara menyampaikan materi pelajaran untuk mencapai suatu hasil belajar yang optimal (Hayes et al., 2017). Hasil belajar peserta didik bukan hanya sekedar nilai tetapi bisa kita lihat dari tiga aspek yaitu pengetahuan, sikap dan psikomotor. Belajar adalah suatu proses yang saling berkaitan antara seorang pendidik dan peserta didik untuk mendapatkan ilmu pengetahuan serta medapatkan hasil pembelajaran yang optimal (Friska Sonia Yulia, dkk. 2020). Dimana didalam proses pembelajaran berlangsung pendidik bisa melihat sejauh mana ilmu yang didapat dalam proses belajar. Serta sikap yang ada pada peserta didik bisa pendidik lihat didalam proses pembelajaran berlangsung. 


\section{METODE}

Jenis penelitian ini peneliti menggunakan metode kuantitatif. Pemeriksaan kuantitatif (Aulia et al., 2019) menyatakan bahwa metode kuantitatif adalah pemeriksaan logis yang secara metodis mendalangi bagian-bagian untuk menemukan informasi sebagai informasi berupa angka. Informasi matematis yang diperoleh peneliti dapat dimanfaatkan untuk memecah data tersebut. Dalam pengumpulan informasi menggunakan instrumen penelitian, pemeriksaan informasi, ditentukan untuk menguji set up spekulasi. Dalam penelitiann ini, strategi yang digunakann adalah teknik eksplorasi dengan rencana pengujian Pre Experimental Design

Terdapat 27 orang siswa pada kelas IV SD Negeri 10/II Sungai Kerjan yang telah ditetapkan menjadi subjek penelitian.Dalam penelitian ini instrumen menggunakan instrumen sebagai pertanyaan tes. Instrument tersebut berupa soal tes yang harus dianalisis dan uji coba terlebih dahulu sehingga soal tersebut layak digunakan oleh peserta didik.

Prosedur pengumpulan informasi yang dilakukan dalam observasi ini adalah metode tes berupa soal pretestt dan posttestt. Tes ini diarahkan untuk mempertimbangkan dan memikirkan hasil yang diperoleh peserta didik dalam ukuran pengajaran dan pembelajaran sebelum dan kemudian setelah penggunaan perlakuan, khususnya metode demonstrasi.

A. Pre-test adalah tes utama yang dilakukan oleh pendidik sebelum menerapkan metode demonstrasi dalam mendidik dan belajar. Tes ini bertujuan untuk melihat seberapa jauh hasil belajar siswa sebelum diberikan perlakuan.

B. Post-test adalah tes terakhir yang dilakukan pendidik setelah menerapkan metode demonstrasi dalam mendidik dan belajar. Tes ini bertujuan untuk melihat dan memikirkan tentang perkembangan normal hasiil belajar siswa setelah diberikan perlakuann.

Dalam penelitian ini teknikk analisiss data menggunakan uji prasyaraat dan uji hipotesiis. Uji prasyaarat dilaksanakan dengan uji norrmalitas yang akan digunakan untuk melihat dan mengukur data yang kita punya berdistribusi teratur atau tidak. Prosedur yang digunakan untuk menguji keteraturan informasi adalah tes Shapiro-Wilk. Uji hipotesis memiliki prasyarat yaitu dengann mengggunakan jenis uji Pairedd Sammple T-Tes. Alasan Uji Paired Sample T-Tes adalah untuk memeriksa apakah ada perbedaan rata-rata antara dua contoh terkait. Pengujian ini memanfaatkan bantuan program SPSS 22. 


\section{HASIL DAN PEMBAHASAN}

\section{Deskripsi Data}

Setelah peneliti melaksanakan penelitian hasil peserta didik kelas IV SD Negeri 102/II Sungai Kerjan memperoleh data pretest dan postest sebelum dan sesudah penerapan metode demonstrasi. Peneliti mendapatkan hasil data yang disajikan menutut nilai tertinggi, nilai terendah, dan nilai siswa yang normal. Berikut ini adalah konsekuensi dari nilai pretestt dan posttestt siswa yang ditunjukkan dalam tabel sebagai berikut:

Tabel 1.4 Data Hasil Prettest dan Posttestt Peserta Didik

\begin{tabular}{|c|c|c|}
\hline Deskripsi Data & Pretestt & Postttest \\
\hline Jumlah Siswa & 27 & 27 \\
\hline Jumlah Nilai & 1710 & 2060 \\
\hline Rata-rata & 63,33 & 76,30 \\
\hline Nilai Tertinggi & 80 & 95 \\
\hline Nilai Terendah & 35 & 50 \\
\hline
\end{tabular}

Sumber: Microsoft Excel 2010

Berdasarkann tabell di atas, dapat disimpulkan bahwa konsekuensi informasi pretest dan posttest peserta didik memperoleh nilai pretest normal 63,33 dan nilai posttest 76,30 . Sejalan dengan itu, sangat terlihat bahwa nilai normal posttest lebih tinggi dari nilai normal pretest. Agar dapat melihat dengan jelas pemeriksaan skor pretest dan posttest siswa, peneliti menyajikan grafik berikut:

Nilai normal pretest dan posttest siswa kelas 4 SD Negeri 102/II Sungai Kerjan. Dapat dilihatt pada gambar di bawah Gambar 2.4 sebagai berikut: 
Perbandingan Pretest dan Posttest

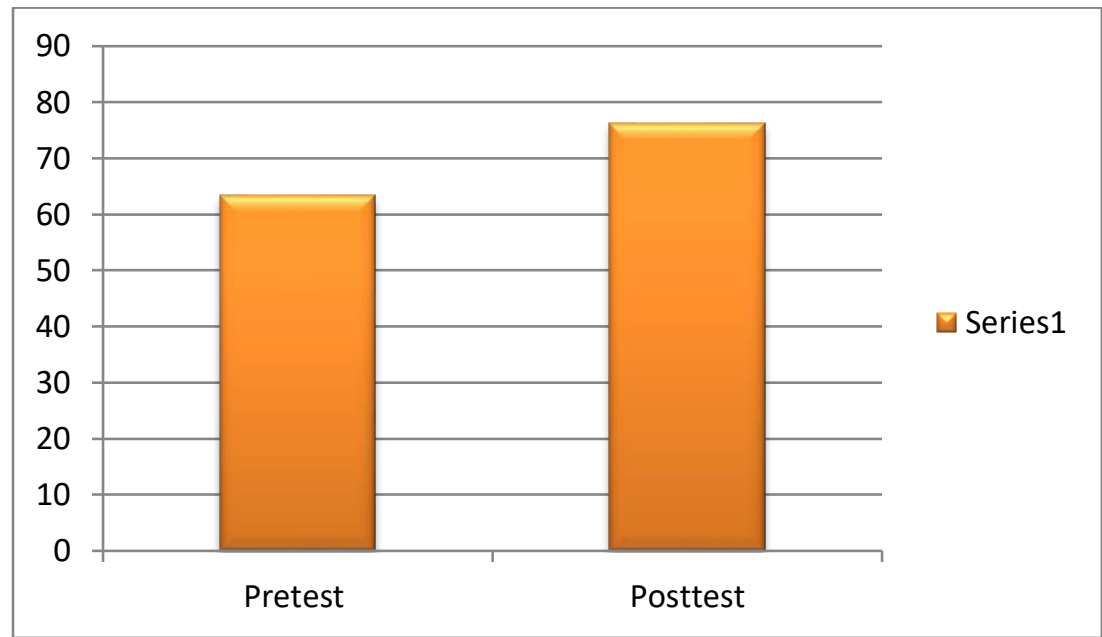

Gambar 1.4 Perbandingan Pretest dan Posttest Peserta Didik

Berdasarkan diagram di atas, dapat diasumsikan bahwa perbandingan nilai pretestt dan posttest siswa kelas 4 SD Negeri 10/II Sungai Kerjan menunjukkkan bahwaa nilai posttestt lebih tinggi dari nilai pretestt. Nilai normal pretest adalah 63,33 sedangkan nilai normal posttest adalah 76,30. Maka selisih antara nilai normal pretest dan posttest adalah 1.297. Dari selisih tersebut dapat dilihat bahwasanya perbandingan nilai meningkat. Artinya, nilai peserta didik meningkat setelah diberikan treatment perlakuan menggunakan metode demonstrasi.

\section{Pengujian Persyaratan Analisis}

Dalam hal penelitian tersebut, peneliti menggunakan uji normalitass dengan bantuan program SPSS 22 menggunakan tes Shapiro-Wilk, dengan aturan bahwa jika nilai hasil lebih besar dari 0,05 , berarti itu biasanyaa berdistribusii normall. Sedangkan jika signifikansi hasil lebih kecil 0,05 artiinya tidak berdistriibusi normall. Data yang di uji normalitas nya yaitu pretest dan posttest. Berikut adalah tabel uji normalitas data pretestt dan posttestt peserta didik kelas IV SD Negeri 102/II Sungai Kerjan. 
Tabel 2.4 Hasil Uji Normalitas Pretest dan Posttest

Tests of Normality

\begin{tabular}{|l|r|r|r|}
\hline \multirow{2}{*}{} & \multicolumn{3}{|c|}{ Shapiro-Wilk } \\
\cline { 2 - 4 } & Statistic & \multicolumn{1}{|c|}{ df } & \multicolumn{1}{c|}{ Sig. } \\
\hline Pretest &, 942 & 27 &, 133 \\
Posttest &, 944 & 27 &, 152 \\
\hline
\end{tabular}

Tabel di atas menunjukkan bahwa signifikansi yang diperoleh data pretest yaitu 0,133>0,05 dan signifikansi yang diperoleh data posttest yaitu 0,152>0,05 artinya data pretest - posttest peserta didiik kelass IV SD Negeri 102/II Sungai Kerjan berdistribusi normal.

\section{Pengujian Hipotesis}

Dalam penelitian ini, peneliti menggunakan uji Paired Sample T-Test yang cocok untukk melihat apakaah terdapat pengaruh terhadap metode demonstrasi yang diterapkan oleh pedidik dalam sistem pembelajaran peserta didik kelas 4 di SD Negeri 102/II Sungai Kerjan. Berikutnya adalaah hasiil tabel uji paired sample t test berikut:

Tabel 3.4 Hasil Uji Paired Samples T Test

\begin{tabular}{|c|c|c|c|c|c|c|c|c|}
\hline & \multicolumn{5}{|c|}{ Paired Differences } & \multirow[b]{3}{*}{$\mathrm{T}$} & \multirow[b]{3}{*}{ Df } & \multirow{3}{*}{$\begin{array}{l}\text { Sig. } \\
(2- \\
\text { tailed } \\
\quad)\end{array}$} \\
\hline & \multirow[b]{2}{*}{ Mean } & \multirow{2}{*}{$\begin{array}{c}\text { Std. } \\
\text { Deviatio } \\
\mathrm{n}\end{array}$} & \multirow{2}{*}{$\begin{array}{l}\text { Std. } \\
\text { Error } \\
\text { Mean }\end{array}$} & \multicolumn{2}{|c|}{$\begin{array}{l}95 \% \text { Confidence } \\
\text { Interval of the } \\
\text { Difference }\end{array}$} & & & \\
\hline & & & & Lower & Upper & & & \\
\hline $\begin{array}{ll}\text { Pair } & \text { Pretest } \\
1 & - \\
& \text { Posttes } \\
& \mathrm{t}\end{array}$ & $\begin{array}{r}- \\
12,9629 \\
6\end{array}$ & $\begin{array}{r}16,0083 \\
7\end{array}$ & $\begin{array}{r}3,0808 \\
1\end{array}$ & $\begin{array}{r}- \\
19,2956 \\
6\end{array}$ & $\begin{array}{r}6,6302 \\
6\end{array}$ & 4,208 & 26 & ,000 \\
\hline
\end{tabular}

Dari tabel di atas dapatt diduga bahwa terdapat pengaruh terhadap hasil belajar peserta didik sebelum dan sesudah penggunaan metode demonstrasi di kelas IV SD Negeri 102/II Sungai Kerjan. Dapat ditemukan pada tabel 13.4 di atas. Pada tabel di 
atas mendapatkan hasil yang signifikan dari uji Paireed Samplle T-Test adalah 0,000 $<0,05$ yang berarti Ho ditolak dan Ha diterima.

\section{PEMBAHASAN}

Berdasarkann hasiil penelitiann peneliti memperoleh data bahwasanya dengan pendidik menerapkan metode demonstrasi didalam proses pembelajaran berlangsung terdapat pengaruh yang positif terhadap hasil pembelajaran peserta didik sebelumm dan sesuudah menggunakan metode demonstrasi. Karna metode demonstrasi sesuai untuk diterapkan di dalam pembelajaran khususnya pembelajaran IPA. Ini juga sejalan dengan penelitian yang menyatakan bahwa metode demonstrasi metode pembelajaran yang tepat yang pendidik terapkan untuk peserta didik di dalam proses belajar dan dapat berpengaruh baik terhadap hasil belajar peserta didik (Aliyah et al, 2014). Karena di dalam metode demonstrasi peserta didik melihat secara nyata materi yang di ajarkan oleh pendidik. Contohnya pada materi gaya dan gerak pendidik langsung menerapkan metode demonstrasi di dalam proses pembelajaran dengan memperagakan suatu barang atau benda yang menyangkut terhadap materi gaya dan gerak adalah benda ketapel dan sepeda. Oleh karna itu peserta didik dan pendidik langsung mencoba dan memperaktekkan ketapel dan sepeda tersebut didepan kelas secara bersamaan. Dengan peserta didik mempraktekkan benda ketapel dan sepeda didepan kelas membuat peserta didik menjadi paham mengenai perbedaan gaya gesek dan gaya pegas. Kemudian peserta didik bisa membedakan antara gaya dan gerak. Dengan menerapkan metode demonstrasi di dallam prosess pembelajarann dapatt membuatt pesertta didik lebih mudah dalam memahamii tentang materii gaya dan gerak. Dan membuat hasil belajar peserta didik lebih optimal.

\section{KESIMPULAN}

Penelitian yang telah dilaksanakan oleh peneliti dapat disimpulkan bahwa terdapat pengaruh terhadap hasil belajar peserta didik. dilakukan pengolahan data dalam penelitian ini dengan menggunakan uji normalitass dan uji paireed samplles $\mathrm{t}$ testt. Hasil uji paired samples t test memperoleh signifikansi maka dapat ditarik simpulan bahwa terdapat pengaruh metode demonstrasii terhadap hasiil belajar pesertaa didiik muatan IPA. 


\section{DAFTAR PUSTAKA}

Aliyah, Syarifah, Mutmainah (2014). Penerapan metode demonstrasi berbantu media animasi software phet terhadap hasil belajar siswa dalam materi listrik dinamis kelas $x$ madrasah aliyah negeri 1 pontianak. 4(2), 1-7.

Silviana, A., Mulyana, E. H., \& Giyartini, R. (2018). Pedadikdatik: Jurnal Ilmiah Pendidikan Guru Sekolah Dasar Penggunaan Model Inkuiri Pendekatan Eksperimental untuk Meningkatkan Penguasaan Siswa terhadap Konsep SifatSifat Cahaya. 5(1), 1-10.

Wiranty, W. (2017). Penerapan metode demonstrasi untuk meningkatkan kemampuan siswa dalam membaca puisi. 284-294.0

Hayes, C., Hardian, H., \& Sumekar, T. (2017). Pengaruh Brain Training Terhadap Tingkat Inteligensia Pada Kelompok Usia Dewasa Muda. Diponegoro Medical Journal (Jurnal Kedokteran Diponegoro), 6(2), 402-416.

Friska, Sonia Yulia. dkk. (2021). Pengaruh Media Konkret Terhadap Hasil Belajar Materi Operasi Hitung Campuran Bilangan Bulat Siswa Kelas IV Sekolah Dasar. JEMS ( Jurnal Edukasi Matematika dan Sains ).

Friska Sonia Yulia. Dkk. (2020). "Pengaruh Model Cooperative Learning Tipe Numbered Heads Together (NHT) Terhadap Minat dan Hasil Belajar Siswa Pada Mata Pelajaran IPS Kelas V Sekolah Dasar”. DE_JOURNAL(Dharmas Education Journal).

Friska Sonia Yulia, Dodi Widia Nanda. (2020) Penggunaan Model Pembelajaran Picture and Picture terhadap keterampilan menulis puisi siswa sekolah dasar. Jhuda_PGSD Jurnal Dharma PGSD

Friska Sonia Yulia, Ana Novitasari. (2020) Peningkatan Hasil belajar Pemecahan Masalah soal cerita pecahan menggunakan strategi polya JVEIT ( Journal Of Vocation education and information technology.

Ade Putri, D. N. A. (2017). Pembelajaran Sains Berbasis Tradisi Sains Islam di Madrasah Tsanawiyah (Gerak Benda menurut Ibnu Bajjah). Phenomenon, O7(2), 164-173.

Saputro, B. C. (2017). Jurnal Mitra Pendidikan ( JMP Online ). 1(9), 925-937. 